\title{
Autorías Transoceánicas. Una baronesa en un boudoir caraqueño
}

\author{
Transoceanic Authorships. \\ A Baronesse at a boudoir in Caracas
}

\section{CECILIA RODRÍGUEZ LEHMANN}

\author{
Universidad Austral de Chile. \\ Correo electrónico: cecilia.rodriguez@uach.cl
}

Entre 1892 y 1915 se publicó en Caracas la revista El Cojo Ilustrado. Esta revista combinaba ilustraciones, fotografías, artículos, anuncios publicitarios, crónicas de moda, literatura, etc. Dentro de ese amasijo textual surgieron elementos escriturales novedosos: las columnas de autoría femenina (muy poco exploradas en la Venezuela del momento), específicamente las columnas fijas escritas por mujeres europeas. A través del análisis de la sección "El tocador de damas", firmado por la Baronesa Staffe, intentaremos ver cómo se introdujo la autoría femenina extranjera en el contexto del entresiglo venezolano y qué papel vino a jugar esa voz femenina transoceánica en el rediseńo del campo autoral.

Palabras clave: autoría femenina, revistas, nación, traducción, exclusión.

Between 1892 and 1915 the magazine El Cojo Ilustrado was published in Caracas. This magazine combined illustrations, photographs, articles, advertising, fashion chronicles, literature, etc. In this narrative context, new scriptural elements emerged: columns written by women (not usual in Venezuela at that time) and specifically those written by European women. In this article, the introduction of the European female authorship in the context of the Venezuelan entresiglo is explored through the analysis of the section "The Ladies Dresser", signed by Baroness Staffe, as well as the role that transoceanic female voices came to play in the redesign of the lettered field.

Key words: female authorship, magazines, nation, translation, exclusion. 


\section{INTRODUCCIÓN}

En 1839 en la revista venezolana La Guirnalda se le pedía al público lector su indulgencia por la ausencia de una mujer que pudiera encargarse de escribir crónicas de moda. El redactor se excusaba argumentando que:

En París, emporio de las ciencias, de las artes y de la elegancia, hay muchas señoras dedicadas a redactar artículos sobre modas y poner al público al corriente de las novedades del buen tono. La Guirnalda no tiene ninguna bella colaboradora que se encargue de esa delicada parte de sus tareas; y en verdad que lo sentimos porque nuestra pluma torpe y desmañada deslustrará a cada instante con sus rasgos la esplendente seda de los vestidos y ajará sin querer los finísimos encajes y las primorosas flores de los tocados (1839: 2).

La escritura sobre trajes y sedas parecía requerir de una delicada pluma femenina que no encontraba en estos territorios quien la empuñara. El tema de la moda -con sus ligerezas y banalidades- lucía poco propicio para ser asumido por la escritura masculina, aparentemente un poco tosca para estos asuntos. ${ }^{1}$ El problema es que -según el redactor- a diferencia de Francia, en Venezuela no había mujeres que pudieran asumir esa "delicada parte de sus tareas". De esta forma, la primera revista venezolana dedicada especialmente a las muejeres dejaba fuera toda posibilidad de una autoría femenina. No se trataba de que la escritura fuera un campo inapropiado para la mujer, sino que aparentemente a las venezolanas no les interesaba. El redactor no se detiene a explicar el porqué de esta ausencia imposible de llenar, lamentándose que las escritoras idóneas, las que el tema parecía requerir, solo existían en París.

Este gesto inaugural, tan temprano en el mundo de las revistas venezolanas, reaparece cada tanto a lo largo del siglo XIX e incluso se interna subrepticiamente en las primeras décadas del XX. La idea de la autoría femenina como un fenómeno propio de las grandes metropolis europeas es bastante persistente y revela mecanismos sutiles de exclusión que habría que mirar con detenimiento.

Si comparamos, por ejemplo, esta pimera revista femenina venezolana con aquella que cierra el siglo, El Cojo Ilustrado (1892-1917), encontraremos vestigios persistentes de estos mecanismos de obliteración. En El Cojo -sin duda la revista más emblemática y difundida del entresiglo venezolano- solo dos mujeres tienen secciones fijas, una francesa, la Baronesa Staffe, y una española, Josefa Pujol de Collado. Las autoras venezolanas aparecen ocasionalmente y ninguna de ellas tiene un espacio tan privilegiado. El Cojo Ilustrado de alguna manera repite el gesto inaugural: la autoría femenina luce más potable y más esplendida si viene de Europa, de un contexto ajeno y distante que parece funcionar bajo otras coordenadas culturales.

\footnotetext{
${ }^{1}$ Sobre la relación entre crónicas de moda y género en Venezuela ver Cecilia Rodríguez Lehmann, Con trazos de seda. Escrituras banales en el siglo XIX (2013).
} 
Este intento por desplazar la autoría femenina tiene como contraparte el importante esfuerzo que estaban haciendo las autoras venezolanas por encontrar espacios en el periodismo y en la literatura. Las revistas creadas y dirigidas por mujeres son un buen ejemplo de ello, pienso, entre otras, en El Ensayo Literario (1872), Flores y Letras (1890), Armonía Literaria (1891), La Lira (1895). De igual forma, pienso en escritoras/periodistas como Polita de Lima, Lina López de Aramburu, Margarita Agostini de Pimentel, Virginia Gil de Hermoso, Rafaela Ramona Torrealba, o Concepción Acevedo de Taylhardat y en cómo buscaban insertarse en el campo cultural. ${ }^{2}$ De alguna forma, la predilección por autoras transoceánicas por parte de cierta prensa liderada por hombres y la lucha por un lugar de enunciación que emprenden algunas autoras locales funcionan como fuerzas en pugna. Es justo desde este juego de fuerzas desde el que quisiera acercarme a una columna como la de la Baronesa Staffe en las páginas de El Cojo Ilustrado.

\section{LAS PALABRAS QUE VIENEN DE LEJOS}

Si bien resulta muy complejo establecer las diferencias entre escrituras nacionales y globales dentro de los procesos de modernización cultural, en especial en espacios tan heteróclitos como las revistas latinoamericanas (Ossandon 2005, Viu 2019), quisiera detenerme aquí en el gesto nacionalista con el que abre el primer número de El Cojo Ilustrado. La publicación se propone, o al menos eso proclama, privilegiar las autorías nacionales por sobre las extranjeras. Su proyecto nacionalista la lleva a establecer una política editorial donde lo local tiene un valor adicional. En el "Prospecto" se nos anuncia que:

Así como para la parte ilustrada, demás está decir que los editores desean con vehemencia que las hojas de esta publicación al texto dedicadas, sean palenque donde brille de preferencia el patrio talento; y para ello excita á los escritores, hombres de ciencia y arte, é industriales venezolanos, á que contribuyan con sus producciones á realzar esta obra de progreso. Todo documento que tenga relación con la Historia Patria, con la de nuestras ciencias, artes é industrias, las lucubraciones de todo linaje que de algún modo representen interés nacional ó revistan carácter genuinamente venezolano, serán acogidas con entusiasmo y deleite, pues la crónica de nuestros heroicos hechos, así como la que demuestre el orijen y desarrollo de nuestra vida intelectual, está aún por comenzarse (1892: 1).

Ese "desear con vehemenecia" la autoría local parece apuntar a la urgencia por establecer una "vida intelectual” propia. Tal como plantea Mirla Alcibíades, José María Herrera Yrigorren, director de la revista, propone "la defensa de la unidad nacional y la lucha

\footnotetext{
${ }^{2}$ La investigadora Mirla Alcibíades (AÑO 1997 O 2004) ha logrado registrar más de 30 revistas dirigidas por mujeres entre 1872 y 1910.
} 
por consolidar los valores de la burguesía emergente" (Alcibíades 1997: 8) . Lo nacional, sin duda, responde a distintas necesidades, pero yo quiero centrarme aquí en la idea de que un campo cultural/escritural que tiende a globalizarse puede generar estas reacciones locales, no solo como meros actos de resistencia sino también como una forma de nivelarse y de entrar a ese diálogo global desde una posición de fortaleza y de solidez cultural. Para entrar al ruedo de la modernización se necesita cierta tracción.

Así, si hemos de creer en esta apuesta nacionalista tan clara, cómo entender entonces que dentro de ese panorama intelectual se privilegien las columnas de mujeres europeas. Dónde quedó el deseo vehemente, el entusiasmo y el deleite. Creo que de nuevo el "Prospecto" nos da pistas importantes. Cuando la revista convoca a los escritores a participar en sus páginas tiene el cuidado de evitar la ambigüedad del término "escritores". Inmeditamente después de la invitación, el redactor acota "Hombres de ciencia y arte, e industriales venezolanos". La idea del escritor como un sujeto universal que puede ser femenino o masculino es aquí delimitada con precisión (Darcie Doll 2004). ${ }^{3}$

Los adelantos culturales parecen estar entonces inevitablemente asociados a una visión de la cultura como un espacio aun muy masculinizado. Habría que recordar, como mencionábamos anteriormente, que ya para estas fechas varias autoras venezolanas (y en general en América Latina) circulaban por periódicos y revistas. ${ }^{4}$

La escritura femenina, tradicionalmente asociada a visiones más románticas, insustanciales o incluso banales (Paulette Silva, Carolina Alzate, Graciela Batticuore), no parecía así poder formar parte de esa Historia Cultural con mayúscula que se deaseaba construir con vehemencia. La revista quiere funcionar como un catálogo cultural -de allí sus meticulosos mecanismos de selección y de exclusión- que permita, por un lado, funcionar como un ente cohesionador de lo nacional, y por el otro, como una plataforma para insertarse en ese mercado cultural globalizado. La historia cultural se escribe hacia dentro y hacia afuera.

Y como aspiramos á que esta Revista sea también vehículo para que en el extranjero sean conocidos los usos, costumbres y progresos de nuestra Patria, suplicamos á todos los lectores de buena voluntad nos hagan la merced de obsequiarnos con dibujos ó fotografías que se rocen y tengan relación con el propósito indicado (1892: 1).

En esa exhibición de los progresos culturales ${ }^{5}$ (desde lo visual y lo escrito) la escritura femenina parece un registro muy débil, que aporta poco. Si vamos más allá del

\footnotetext{
${ }^{3}$ Tal como nos recuerda Darcie Doll, "si bien pudiera pensarse que la autoría femenina es asumida por la noción de autor, siguiendo el género masculino como universal, ella resulta ser justamente lo contrario: más que ingresar en el campo cultural como autora, la mujer ha quedado largo tiempo fuera, tal como ocurrió en la categoría de ciudadano" (2014: 73).

${ }^{4}$ De hecho, algunas de estas escritoras aparecerían posteriormente en algunos números de El Cojo Ilustrado.

5 Paulette Silva $(2000$, 2006) desarrolla la idea de la revista como espacio de exhibición de un proyecto de modernización del país. De igual forma Beatriz González-Stephan (2006) estudia la idea de la exhibición como un registro fundamental para entender el entresiglo venezolano.
} 
"Prospecto" y revisamos con detenimiento los autores que publican en su primer ańo de vida encontraremos datos interesantes. En efecto, veremos que en la revista predominan los escritores venezolanos (aunque hay un importante número de traducciones), mientras que las autoras nacionales no tienen ninguna cabida. En este primer año escriben 162 hombres y solo tres mujeres, de esas tres todas son extranjeras: Emilia Pardo Bazán ("En el nombre del padre", "Nieto del Cid", "El premio gordo", "A la puerta del Monasterio"); Soledad Acosta de Samper ("Traición y castigo"); y la Baronesa Staffe (15 entregas de El tocador).

Esta ausencia total de autoras venezolanas será subsanada en los años siguientes en donde tímidamente veremos aparecer algunas escritoras locales. En 1893, por ejemplo, publicarán 106 hombres y aparecerán por primera vez cuatro autoras venezolanas: Pepita Calcaño de Caragol, Polita de Lima, Margarita de Pimentel e Ignacia Pachano de Fombona (estas últimas bajo el pseudónimo común de Blanca y Margot). En 1895 aparecieron varios relatos femeninos y las fotografías de sus autoras. No obstante, como podemos ver, las cifras siguen siendo significativamente bajas.

Podríamos pensar que El Cojo comienza a abrir espacios para las colaboradoras venezolanas como pequeñas muestras de su amplitud intelectual y de su grado de modernización. Si bien la autoría femenina local no parecía muy importante a la hora de construir una Historia Cultural, sí lo era para mostrar una cara moderna-liberal. La revista emblema de la modenización venezolana debía incluir dentro de sus avances esos otros registros que, aunque menores y esporádicos, daban cuenta del lugar de la mujer dentro de este proceso. Tal como señala Paulette Silva:

El reacomodo que significó la modernización, y el deseo de exhibir los cambios, incluía mostrar a las nuevas mujeres, civilizadas, patriotas y muy virtuosas, dulces ángeles del hogar y doncellas muy sensibles (como corresponde a una sociedad civilizada), que también sabían ser buenas maestras y aprovechar sus ratos de ocio para escribir ficciones que reproducen todos estos valores con fines pedagógicos (142).

La revista se abre a un tipo de escritura femenina local que no cuestione la función primordial de la mujer como centro del hogar. Como bien señala Silva son ángeles del hogar que también escriben. Esta inclusión ocasional de escritoras locales modernas contrasta con una larga tradición cultural venezolana que incluyó de manera muy temprana a autoras extranjeras. De hecho, como bien señala Mirla Alcibíades (2004), la primera aparición de un texto femenino en la prensa venezolana fue de una extranjera, la colombiana María Josefa Acevedo. De igual forma aparecieron a lo largo del siglo varias novelas y folletines escritos por francesas y españolas que circularon profusamente por los diarios locales.

La Baronesa continúa así con una larga tradición que privilegia la producción femenina foránea, pero a su vez, su dilatada y sobresaliente presencia dispara una serie de interrogantes: cómo se insertó esta autora francesa dentro del campo cultural del entresiglo venezolano; cómo dialogó con otras autorías femeninas; cómo se refuncionalizó su escritura dentro de un tinglado escritural muy distinto al de su lugar de origen; por qué sobrevive la predilección por la autoría femenina foránea en un momento tan tardío. 


\section{Una Baronesa y un Cojo}

En 1892 aparece por primera vez en El Cojo Ilsutrado una columna titulada El tocador. Esta columna firmada por la Baronesa Staffe viene precedida de una breve introducción en la que se nos dice:

La Baronesa Staffe, autora de un libro muy leído acerca del arte de conducirse en sociedad, acaba de publicar otro no menos interesante y que titula El Tocador. En obsequio a nuestras lectoras, traduciremos de él los más notables capítulos que servirán de guía y norma a nuestras bellezas caraqueñas. Publicamos a continuación el primero (1 de enero de 1892: 20).

En esta pequeña presentación se nos ofrecen pistas importantes de cómo se reinserta esa escritura femenina en la revista y en el entresiglo venezolano. Para comenzar, la misma presencia de la introducción -hecha por un redactor anónimo- nos habla de la mediación entre esas "lectoras" y el libro de donde se extraen los fragmentos. La escritura femenina prologada, comentada, editada, corregida por un redactor masculino es una práctica muy común en el siglo XIX de la que la Baronesa no escapa. ${ }^{6}$ La presencia del paratexto masculino es una forma usual de intervenir la escritura femenina (Batticuore 2005), sin embargo, en este en particular, hay unos signos distintivos en los que vale la pena detenerse.

Para empezar, el redactor presenta a la Baronesa como "autora" (no como un ángel del hogar que escribe), una autora de libros muy leídos e interesantes. ${ }^{7}$ Un gesto no menor después de que hemos visto las especificaciones de género del "Prospecto" de la revista. Ella viene, además, legitimada por el grado de popularidad de su primera obra. Es una autora de best-seller reconocida a nivel internacional, ${ }^{8}$ se trata de una escritora profesional, no una mujer que escribe versos en sus ratos libres. Así, la Baronesa forma parte de un mercado literario que ya tiene sus nombres sobresalientes, sus cifras de ventas, sus maneras de popularizarse.

El mismo nombre de la Baronesa, como era de suponerse, es parte de esta empresa, se trata de un pseudónimo. Su verdadero nombre era mucho menos llamativo, Blanche Augustine Anyele Soyer. Y si bien el pseudónimo es un recurso muy usado por hombres y mujeres para escribir en la prensa decimonónica, creo que en este caso no se trata de una veladura, un discreto encubrimiento, sino de un gancho comercial que la acerca a

\footnotetext{
${ }^{6}$ Para un estudio detallado de estas intervenciones véase el libro de Graciela Batticuore, Mujeres románticas (2005).

${ }^{7}$ La manera cómo las autoras son presentadas a los lectores de revistas merecería un estudio más detallado que se detuviera en las diferencias que se dan entre autoras latinoamericanas y autoras europeas que han entrado en otros círculos de comercialización.

8 También son importantes las marcas que han desaparecido, por ejemplo, sus vínculos familiares (madre, esposa, hija), su situación sentimental (la siempre tranquilizadora situación conyugal), su nombre de pila. La Baronesa resalta por su título nobiliario, su apellido extranjero y por ser autora de libros populares.
} 
las actrices, bailarinas y cantantes de la época. La escritora de estos tempranos best-sellers requiere de un nombre de artista. Resulta muy interesante ver cómo en el libro original editado por Victor Havard, también se omite el nombre verdadero de la autora y se acude a métodos de mercantilización de la escritura muy explícita. En la portadilla de Le Cabinet de Toilette (1891) se lee: "Du meme auteur Usages du Monde. Régles du savoir-Vivre dans la Societe Moderne". De igual forma se menciona que este libro lleva ya cinco ediciones y que cuesta cinco francos. Por último se nos advierte "Reserve de tous droits de propiété littéraire en France et a l'étranger". Todas estas marcas comerciales nos hablan de la escritura de la Baronesa como "propiedad literaria". Una mercancía cuyos reditos hay que promocionar pero también cuidar. La advertencia por escrito de los derechos de propiedad tanto en Francia como en el extranjero nos muestran los alcances que tiene el libro en un mercado que desdibuja fronteras así como también lo consolidado que se encuentra ese mercado.

Estas características permiten entender por qué El Cojo describe los fragmentos de El Tocador como un "obsequio" para las "bellezas caraqueñas". Los fragmentos del libro son presentados como atractivas mercancías traídas de Paris. De alguna manera, la revista incorpora la autoría de la Baronesa como una pieza elegante, foránea, que intenta alagar a la lectora local. Un procedimiento parecido al de los figurines de moda traídos de París o a las lujosas ilustraciones a las que también se calificaba de "obsequio" para la lectoras. En el fondo, la autoría europea carga el halo de las mercancías suntuosas y transatlánticas de una manera no muy distinta a la de los guantes, los vestidos, los perfumes o los figurines.

Figura 1. Portada de la primera edición de El Tocador de damas

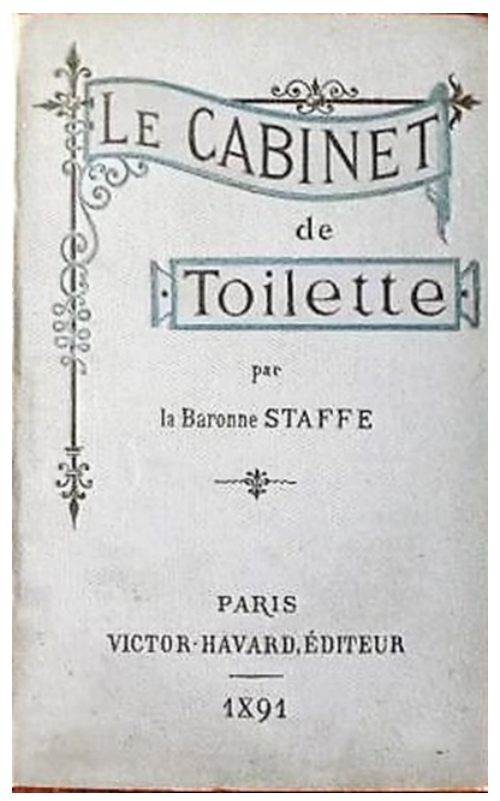


Figura 2. Portada de una de las traducciones españolas del libro más vendido de la Baronesa La elegancia en la vida social

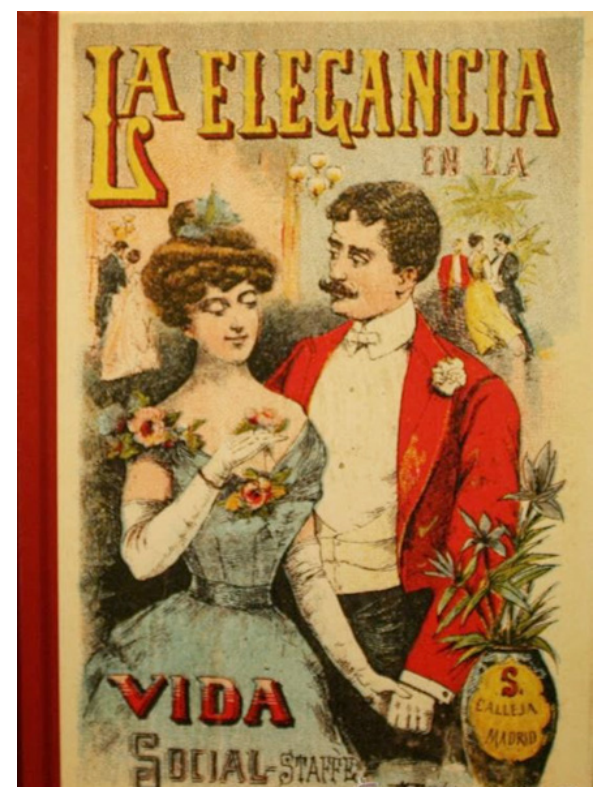

Interesante poder contrastar esta presentación de la Baronesa con la primera que se hace a una autora venezolana en $E l$ Cojo. Se trata de un texto de Polita de Lima titulado "Luz y sombra", y que es introducido por J.R.Pachano. ${ }^{9}$ Dice el prefacio que se trata de:

un juguetillo escrito para el álbum de una amiga; pero al propio tiempo muestra acabada de belleza de estilo y de alta concepción filosófica (...) perfumado con el esquisito aroma de la modestia, tanto más resaltante cuanto que quien de tal suerte pretende ocultarse bajo la sombra, no podría vivir sino en las amplias esferas de la luz; ó en las tinieblas, semejante á una luciérnaga ( $\mathrm{N}^{\circ} 40.18$ de agosto de 1893).

Si la baronesa es introducida como una autora de renombre dentro del mercado literario, Polita de Lima es presentada como una autora de juguetillos, más cercana a la escritura íntima y doméstica del álbum. Esa escritura semiprivada y amateur entra al espacio público por la gentileza de su presentador quien encuentra el suficiente mérito en ella como para ser compartida en las páginas de la revista. La modestia queda así salvaguardada por este intermediario que hace visible a la escritora-luciérnaga (Batticuore). La Baronesa y la luciérnaga están unidas por la noción de la escritura como entretenimiento pero se

\footnotetext{
${ }^{9}$ Se trata del General Jacinto Regino Pachano, importante escritor y figura pública.
} 
legitiman en lugares muy distintos; ellas perfilan formas de entrar al espacio público y al campo escritural de maneras antagónicas. Insisto en que esas divergencias van de la mano de su procedencia y de la manera cómo se introduce la autoría foránea en el contexto local. Para ahondar en este punto volvamos de nuevo a nuestro obsequio de París.

\section{Un OBSEQUIO DESARMADO}

El obsequio que han recibido las lectoras de la revista no es un libro de París, sino la selección y traducción de algunos de sus fragmentos, "los más notables". El libro ha sido desarmado y vuelto a reconstruir de otra manera. No se trata de la serialización propia de los folletines, ni de una entrega por partes, sino de una reconstrucción de los pedazos. El redactor escoge y traduce -ya sabemos de sobra las mediaciones de la traducción- aquellos fragmentos que le resulten más potables. De hecho si cotejamos los fragmentos incluídos en El Cojo con el libro original veremos que existen muchas variaciones. Para empezar, el orden, el primer fragmento que nos presenta la revista corresponde a la tercera parte del libro "Las coqueterías permitidas"; la entrega siguiente, "El santuario de la mujer", corresponde al primer texto de la primera parte. De esta forma, el redactor va estableciendo un orden que no tiene nada de ver con la estructura establecida por la Baronesa.

Esta desestructuración del texto viene de la mano de otras intervenciones. En el paso del libro al fragmento el proceso del recorte se vuelve también fundamental, dónde comienza y dónde termina cada entrega, qué se deja fuera y qué se incluye. Si volvemos de nuevo al cotejo con la fuente original veremos que el redactor establece cortes en cada entrega. En líneas generales el principio del texto coincide con el principio de cada capítulo pero el final depende de las decisiones del editor (el espacio sin duda es un factor muy importante). En algunas entregas aparece el capítulo del libro completo en otras tan solo un fragmento. Así, el redactor construye, de alguna forma, otra obra hecha a partir del reordenamiento y de la fragmentación. Una obra donde la autoría es, por decir lo menos, problemática.

Un detalle en la primera entrega de $E l$ Tocador me permite reforzar este punto. Después de la introducción del libro y una vez que nos adentramos en la obra de la Baronesa -obra fragmentada, reescrita, reordenada- el redactor hace una pequeña aclaratoria en un corchete: "[Lenguaje de la Baronesa Staffe]" (enero 1892: 10). El corchete es una intervención ambigua, por un lado, pareciera marcar una suerte de respeto por el texto original al que sólo se le introducen marcas claramente visibilizadas y, por el otro, implica una intromisión en el texto. El ejemplo que utilizamos aquí es aun más problemático ya que que está señalando justamente algo que asumiríamos como obvio, la autoría. En este corchete, el redactor hace referencia a la frase inmediatamente anterior, en ella la Baronesa interpela a sus lectoras y las llama "Hermanas mías". El editor intenta evitar aquí cualquier confusión entre su labor como traductor-editor y el texto de la Baronesa; está intentando evitar que se le atribuya erroneamente ese amoroso apelativo. La aclaratoria, sin duda, visibiliza la posibilidad de la 
Figura 3. En esta imagen vemos cómo aparecen los fragmentos en la revista así como un elemento fundamental: la imagen que lo acompaña y que es introducida por el editor

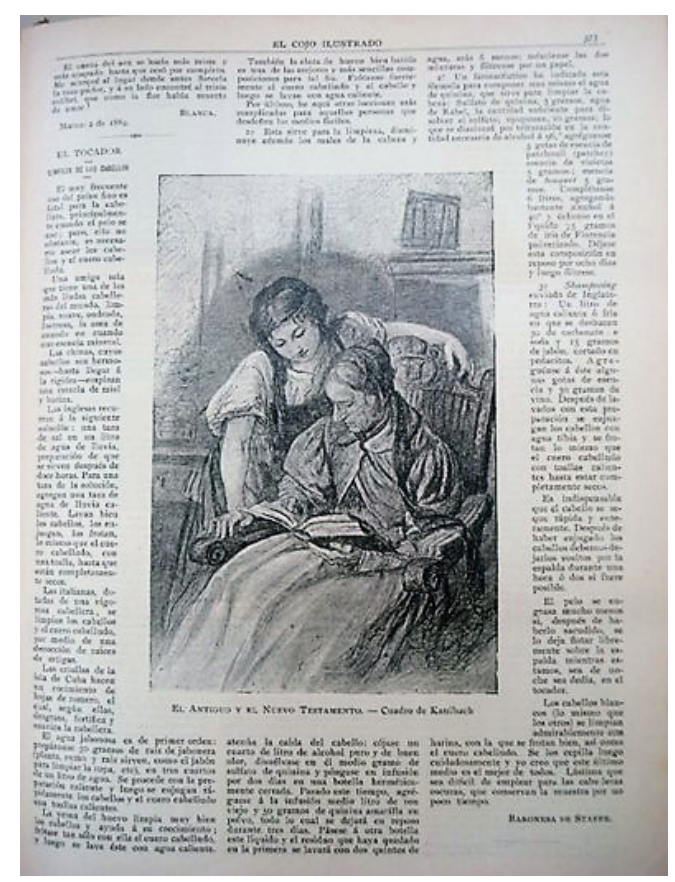

confusión autoral, precisamente porque la autoría es un terreno movedizo que el corchete intenta aclarar un poco. Por un lado, el traductor se desmarca y, por el otro, inerviene el texto a partir de operaciones más sutiles y menos rastreables. Quién traduce, quién edita el texto, quién selecciona, quién ilustra ${ }^{10}$ ¿se trata de la misma persona?

La razón de estas alteraciones es difícil de determinar (atractivo comercial, censura, control moral, adecuación al contexto venezolano), pero lo que interesa en este momento es la alteración misma, la licencia que tiene el redactor para intervenir la estructura del texto. Los procesos de selección, recorte, reordenamiento, reescritura, son propios de espacios como las revistas y la prensa. El cambio del formato y del soporte de la prensa al libro y del libro a la prensa implica, de cierta forma, un proceso de reacomodo y readaptación. El mismo Cojo está lleno de traducciones de novelas, de poesía, de fragmentos de libros, en donde la intervención es moneda corriente. Sin embargo, más allá de esta práctica común, creo que la ruptura de la linealidad del libro de la Baronesa y su reordenamiento obedece a dos razones adicionales, por un lado, a que se trata de un manual que tiene múltiples

${ }^{10}$ Las ilustraciones que suelen intercalarse con el texto, así como los textos que lo rodean, lo anteceden, etc. ofrecen otro tipo de intervenciones pero que por razones de espacio no analizaremos aquí. 
entradas y que pareciera poder funcionar desde la fragmentariedad de sus partes y, por otro lado, a que el reordenamiento permite depurar -y eliminar cuando es necesario- los excesos de la vida mundana. La muy popular Baronesa no es una escritora de ficción ni de relatos románticos sino de manuales de la vida elegante; manuales que pueden ser muy útiles puestos que sirven de "guía" y "norma", pero que también ofrecen tortuosos desvíos en esos caminos que entrelazan la vida elegante parisina con un boudoir caraqueño.

El obsequio de París tiene sus triquińuelas, por un lado, como todo manual de comportamiento sirve para disciplinar y ordenar el cuerpo individual y nacional (GonzálezStephan), ${ }^{11}$ pero, por el otro, contiene ciertas formas de la vida elegante que resultan excesivas para una sociedad venezolana que aun lucha por establecer un cierto orden y una cierta mesura. El rearmado y la selección por parte del traductor y del editor permiten un proceso de reconstrucción en donde las aristas peligrosas -la erotización del cuerpo femenino, por ejemplo- son limadas para evitar los cortes. Las mercancías también requieren ser editadas.

\section{5. "No BASTA SER HONRADA Y BUENA MADRE"}

"No basta ser honrada y buena madre para conseguir de su marido la permanencia en el hogar; se hace necesario ser a lo menos, mujer bonita y agradable" (1892). Así comenzaba la primera entrega de la Baronesa. El capítulo elegido se titula "Las coqueterías permitidas" y se trata de una exhaltación de la belleza física y de los procesos que permiten fabricarla. La Baronesa se queja del atuendo aburrido y recatado de las mujeres y las increpa a subsanar ese descuido:

llevamos vestidos grises, de color neutro, que nos dan un aire opaco, triste, mortecino; calzamos unos pantuflos burdos, sin gracia; ocultamos los brazos que pueden servir de segura seducción ; nos echamos á cuestas batas bombachas que nos hacen el cuerpo como si fuera todo hecho de una pieza, sin contornos; nos trenzamos el pelo sin gusto, perdiendo con esto uno de los más seguros medios de embellecernos (10).

Las curvas, la piel, el cuerpo -eludidos por tanto tiempo como terremos pecaminosos- son rescatados aquí como elementos que deben ser exhibidos. Se exhiben los brazos torneados, la silueta, la cintura, los pies. Al cuerpo hay que sacarle provecho, no ocultarlo, de alguna manera hay que erotizarlo, volverlo un instrumento de deseo. La

\footnotetext{
${ }^{11}$ Dice Beatriz González-Stephan (1996) a propósito del siglo XIX venezolano: "Constituciones, gramáticas y manuales comparten en su espíritu nuclear el ser discursos que en su forma de leyes, reglamentos y normas no sólo previenen de la infracción o error, del castigo o culpa, sino que asumidos sistemáticamente a través del ejercicio continuo van formando un cuerpo policial subjetivado, una representación interiorizada en cada individuo. No persiguen el castigo sino la prevención. Se mueven en el campo de las prohibiciones y de las amenazas sistemáticas para infundar la adecuada dosis de temor en cada individuo ante su posible exclusión o marginamiento de los escenarios legitimados por la autoridad estatal” (González-Stephan 26).
} 
misma palabra "seducción" (séductions en el original) nos habla de una manera muy distinta de entender la relación de la mujer con su propio cuerpo y con el cuerpo del otro. Para la Baronesa, la belleza y la seducción no son innatas, son habilidades que se cultivan, que están vinculadas con el esfuerzo y la inteligencia "servez- vous de votre intelligence pour rester jolie ou le devenir" (262).

Claro está que todo esta erotización y esta puesta en escena del cuerpo femenino tiene una vuelta al orden; esta exhibición performática y voluntariosa resulta necesaria para conservar al marido, para mantener la felicidad doméstica. Se trata de una estrategia para evitar las tentaciones externas y para que el marido permanezca "enamorado" y en casa. Las tretas de las aristocráticas damas de la vida mundana son puestas aquí al servicio de la vida doméstica burguesa. De allí que la Baronesa hable de "las coqueterías permitidas", aquellas que se dirigen al marido y no al vanidoso territorio de los salones.

Resulta curioso que los redactores de El Cojo escojan este fragmento para comenzar la columna de la Baronesa, un fragmento que en el libro original solo aparece hacia el final, en la página 200. El libro está dividido en cuatro partes: "Agencement et amueblement", "Soins corporele en général", "Conseils et recettes", "Bijou, Chiffons et Dentelles". El Cojo comienza por la última parte y luego se concentra en la primera en donde se describen los detalles del tocador como espacio de cuidado y de embellecimiento.

A riesgo de cometer algún exceso interpretativo, creo que "Las coqueterías permitidas" permite establecer desde un principio unas ciertas reglas del juego: los consejos que brinda la Baronesa sólo son válidos dentro del espacio doméstico y para procurar la felicidad conyugal. Este punto de partida hace que el resto de los fragmentos deban ser leídos bajo esta clave interpretativa. Es una clave que también está en el libro original pero que solo aparece en el final, después de que hemos transitado por maneras de mirar el cuerpo que tienen sus riesgos. No quiere decir que el manual no esté impregnado de esta carga sino que ella se encuentra dispersa y a veces se disuelve peligrosamente. El manual de la Baronesa se mueve entre una vida de salón aristocratizada y mundana que se está dejando atrás y una nueva aburguesada que no deja de tener resabios de la anterior. En un capítulo del libro que El Cojo decide no incluir podemos ver estos mundos que se interpelan y se interceptan:

Sans imiter leurs sacrifices qui ne sont pas toujours compatibles avec la vie que mène une honnête et simple mère de famille, ne voulez-vous pas lutter, vous aussi, avec les armes permises que je vous ai indiquées, pour arrêter la vieillesse et l'enlaidissement? Cela vous sera plus facile qu'à elles. La saine activité où vos journées s'écoulent vous est favorable, tandis que les mondaines ont sans cesse à réparer les rudes fatigues de leur vie de plaisirs et de déplacements (1891: 266). ${ }^{12}$

\footnotetext{
12 "Sin imitar sus sacrificios que no son siempre compatibles con la vida que lleva una honesta y simple madre de familia, ¿no quisiera usted también luchar con las armas permitidas que le he indicado para detener la vejez y el deterioro? Eso le resultará más fácil que ellas. La sana actividad en la que transcurren vuestras jornadas os es favorable, mientras las mundanas se afanan sin cesar en enmendar las rudas fatigas de su vida de viajes y placeres" (traducción es mía).
} 
Si bien entre las grandes mundanas y las honestas madres de familia burguesa hay diferencias enormes no deja de haber entre ellas intereses en común: evitar el envejecimiento, embellecerse, exhibir el cuerpo, seducir, etc. La noción de que la belleza es un artificio que se produce en el tocador y no una emanación de las bondad natural del espíritu establece un puente con una vida mundana de la cual se reniegan algunos elementos pero se rescantan otros.

En la siguiente aparición de la Baronesa en El Cojo, nos encontramos con los artificios que se producen en el tocador. Este espacio, privado por excelencia, es abierto a la mirada pública y se le describe como "un santuario para la mujer". Lo que ocurre allí debe ser un ritual secreto, especialmente para el marido, pero que paradójicamente la escritura devela:

Nuestros maridos deben hallarnos siempre frescas, dulces, bellas como una flor, pero es preciso que nos crean adornadas como los grandes lirios por magia natural y divina. Bueno es que ignoren que nuestra belleza se adquiere ó se conserva á costa de mil cuidados, que ni siquiera sospechen que poseemos los medios para embellecernos, medios inocentes, convengo en ello, pero que le harían quizá burlarse y sonreír (21).

Esa belleza que se construye ${ }^{13}$ en el tocador parte de una suerte de engaño inocente. El cuerpo no se presenta como un lugar legible sino como un cuerpo construido y engañoso. ${ }^{14}$ Y si bien toda esta transmutación se ejecuta para el bien del marido no deja de ser riesgosa. La propuesta de la Baronesa viene a plantear formas de ver el cuerpo y de relacionarnos con él que resultan, a lo menos, problemáticas. Recordemos que, tal como apunta Antoine de Baecque en su libro Corps de l'histoire, en el siglo XIX el cuerpo suele concebirse como "le grand stectacle de la transparence" (el gran espectaculo de la transparencia). La puesta en escena del cuerpo moderno parte de la noción de que este puede ser leído y descifrado como si se tratara de un texto, no sólo a través de prácticas ligadas a la ciencia, tales como la frenología, sino tambien a través de la simple observación. Como señala Silvya Molloy en su conocido estudio sobre la pose, en el siglo XIX "los cuerpos se leen (y se presentan para ser leídos) como declaraciones culturales” (1994:129).

La Baronesa, al hablar de la construcción de ese cuerpo y de su reforma a través de los trucos y los engaños del tocador se aleja de esta transparencia para internarse en el

\footnotetext{
${ }^{13}$ No puedo dejar de vincular esta noción de la belleza como un artificio, con las propuestas estéticas del modernismo latinoamericano y como en ellas también se recurre a la noción de la belleza como constructo y no como un producto de la naturaleza. Aunque parezcan registros muy distintos, creo que hay formas de concebir la belleza que se cuelan por prácticas disímiles. Recordemos también que escritores como Baudelaire o Wilde, en el ámbito europeo, también hicieron del arreglo personal y de la vestimenta unas prácticas estéticas legítimas.

${ }^{14}$ Para un análisis de la manera cómo se lee el cuerpo en distintos contextos históricos ver el libro Historia del cuerpo (2005) coordinado por Alain Corbin, Jean Jacques Courtine y Georges Vigarello.
} 
mundo de las simulaciones y enmascaramientos aparentemente más cercanos a las temidas mundanas de los salones de París. No olvidemos además el seudónimo que utiliza Blanche Augustine Anyele Soyer, el título nobiliario la ubica como parte de un linaje, es heredera de esos salones mundanos aun cuando los refuncionalice.

Así, la idea de que quien escribe se haga llamar baronesa nos presenta una autoría compleja. Una autora-baronesa nos remite inevitablemente a un espacio aristocrático que parece un tanto fuera de lugar, no obstante, sabemos que no es un título real, sino una estrategia discursiva posiblemente pensada en términos de mercadeo. Se trata de una treta, un simulacro.

De nuevo un paratexto nos da una clave, en el libro original el editor nos dice: "Cést ce qui explique le succès et la réputation de cet ouvrage parmi les gens du monde et dans les familles qui ne trouvaillent plus dans les ouvrages similaires aujourd'hui démodés l'autorité que donne à celui-ci la notoriété mondaine et littéraire de la Baronne Staffe" (354) ${ }^{15}$.

La autoridad de la Baronesa como escritora viene dada tanto por su notoriedad en los salones mundanos como por su reconocimiento en el mundo literario. De alguna forma ambos aspectos se fusionan para apuntalar la figura de una escritora mundana y profesional. Uno de los aspectos llamativos de esta autoría tiene que ver con las marcas que han desaparecido tanto en el libro como en la columna. La Baronesa no figura como madre o esposa, como un ángel del hogar que también escribe (Silva), sino como una autora/ socialité popular. Los breves paratextos masculinos que la acompañan insisten en resaltar esa doble condición.

¿Cómo es posible entonces que esta baronesa aristocrática y seductora resulte potable para los editores de El Cojo Ilustrado?, ¿Por qué abrirse a los riesgos que ella encarna?:por qué incluso preferir su voz a la de las escritoras locales? Por una parte, como intento haber mostrado, porque esa autoría podía ser traducida, reordenada, cortada, depurada, potabilizada, sin mayores tapujos y sin mayores explicaciones. Por otro lado, porque se presentaba como una mercancía de importación, un regalo exótico, un producto comercial muy exitoso. Y, por último, porque presentaba la autoría femenina como una práctica foránea, metropolitana, alejada de la cotidianidad de las venezolanas aparentemente ocupadas en otros menesteres. La Baronesa es como las mujeres de París, esas mismas que caminan por las calles y bailan can-can.

\section{Posibilidades/EXCLUSIONES}

El caso de la escritora/baronesa nos permite ver formas de autoría femenina que circularon no solo en Europa sino que se reinsertaron en periódicos y revistas

\footnotetext{
15 "Esto es lo que explica el éxito y la reputación de esta obra tanto entre la gente de mundo como en las familias que no encuentran en obras similares, hoy en día pasadas de moda, la autoridad que a esta le confiere la notoriedad mundana y literaria de la Baronesa Staffe" (La traducción es mía).
} 
latinoamericanas. Formas profesionalizadas y mercantilizadas que parecen alejarse de otras estrategias discursivas utilizadas por sus pares femeninas ${ }^{16}$, pero que también permearon y transformaron el campo cultural venezolano y latinoamericano en general. Estas autorías transoceánicas resinsertadas en América Latina terminaron jugando un papel importante en la manera en cómo se entendió la escritura hecha por mujeres. Ellas permitieron pensar las distintas posibilidades autorales de una mujer, pero también funcionaron, paradójicamente, para desplazar a las escritoras locales, para suplantarlas con unas voces que sonaban lejanas y autorizadas en otros espacios. La autoría foránea al pasar por procesos de traducción, selección, reordenamientos y reinserciones a veces resultaron más manejables para el mundo letrado masculino. Todo esto nos lleva a preguntarnos si es posible leer estas inclusiones de autorías femeninas foráneas como velados procesos de exclusión y de desplazamiento más que de apertura.

La aparición de la Baronesa en un boudoir caraqueño nos mostró como la escritura femenina funcionó como una mercancía de lujo que conectaba a la incipiente burguesía venezolana con una afamada baronesa que enseñaba el artificio de la belleza y de la exhibición de sus formas. Nos mostró cómo esa mercancía podía ser enmendada y reacomodada por los traductores y editores masculinos convirtiendola en una pieza funcional dentro del proyecto liberal. Nos mostró, por último, como las palabras que vienen de lejos se amoldan a otros mapas culturales para producir otros efectos, otros deseos, otras carencias, y, a ratos, otras exclusiones.

\section{Obras CITADAS}

Alcibíades, Mirla. 1997. Publicidad, comercialización y proyecto editorial de la empresa de cigarrillos "El Cojo": (1873-1892). Caracas: Fundación Centro de Estudios Latinoamericanos Rómulo Gallegos, . 2004. La heroica aventura de construir una república. Caracas: Monte Ávila Editores.

1917. Literatura y nación en El Cojo Ilustrado : la "intima satisfacción" de Jesus Maria Herrera Irigoyen. Caracas: Fundación Bigott.

Alzate, Carolina y Darcie Doll (Coomp.) 2004. Redes, alianzas y afinidades. Mujeres y escritura en América Latina. Bogotá: ediciones Uniandes/ Universidad de Chile.

Batticuore, Graciela. 2005. La mujer romántica. Lectoras, autoras y escritores en la Argentina: 1830-1870. Buenos Aires: Edhasa.

Corbin, Alain, Jean-Jacques Courtine, Georges Vigarello. 2005. Historia del cuerpo. Madrid: Taurus.

De Baecque, Antoine. 1993. Le Corps de l'Histoire. París: Calmann-Lévy

\footnotetext{
${ }^{16}$ Pienso, por ejemplo, en las estrategias que nos describe Batticuore (2005) y en las distintas maneras de asumir la autoría: "autoría escondida", "autoría exhibida", "autoría intervenida", "autoría inteceptada”, etc.
} 
Doll, Darcie. 2004. "Variaciones de la autoría en escritoras chilenas de finales del siglo XIX y comienzos del XX". En Alzate, Carolina y Darcie Doll (Coomp.) Redes, alianzas y afinidades. Mujeres y escritura en América Latina. Bogotá: ediciones Uniandes/ Universidad de Chile.

Gonzáles-Stephan, Beatriz y Jens Andermann. 2006. Galerias del progreso. Museos, exposiciones y cultura visual en América Latina. Buenos Aires: Betariz Viterbo. . 1996. "Economías fundacionales. Diseño del cuerpo ciudadano" en González-Stephan (Coomp.) Cultura y tercer mundo. Caracas. Nueva Sociedad. PP. 17-47.

Ossandon, Carlos y Eduardo Santa Cruz. 2005. El estallido de las formas. Santiago: Universidad Arcis/LOM.

Molloy, Silvya. 1994. "La política de la pose" en Ludmer, Josefina (comp). Las culturas de fin de siglo. Rosario: Beatriz Viterbo.

Rodríguez Lehmann, Cecilia. 2013. Con trazos de seda. Escrituras banales en el siglo XIX. Caracas: Fundavag ediciones

Silva Bauregard, Paulette. 2006. "Un lugar para exhibir, clasificar y coleccionar: la revista ilustrada como una galería del progreso". En Andermann, Jens y Beatriz GonzálezStephan (ed). Galerías del progreso. Museos, exposiciones y cultura visual en América Latina. Buenos Aires: Betariz Viterbo. . 2000. De médicos, idilios y otras historias. Bogotá: Convenio Andrés Bello.

Staffe, Baronesa. 1891. Le cabinet de toilette. Paris: Victor Havard Editeur.

Viu, Antonia. 2019. Materialidades de lo impreso. Revistas Latinoamericanas 1910-1950. Santiago: Ediciones Metales Pesados.

\section{ReVISTAS}

El Cojo Ilustrado. Caracas. 1892-1915

La Guirnalda. Caracas. 1830 